\title{
5 The object biography
}

\author{
Adam Drazin
}

Whatever happened to commoditisation? The Social Life of Things (Appadurai 1986b) opened up the anthropological study of material culture in ordinary, everyday life in an important way. It contained Appadurai's much-quoted exhortation to 'follow the things':

We have to follow the things themselves, for their meanings are inscribed in their forms, their uses, their trajectories. It is only through the analysis of these trajectories that we can interpret the human transactions and calculations that enliven things. [...] it is the things-in-motion that illuminate their human and social context.

(ibid.: 5)

Not a specific methodology, nor part of an interdisciplinary field of MCS, this perspective can be used in anthropology to inspire critical analyses of cultures of value. Appadurai's essay is accompanied by Igor Kopytoff's insightful piece, 'The Cultural Biography of Things,' which traced oscillations in the social lives of objects, between states of cultural specificity and generality. When things are possessed by certain people, they present particular, even particulate, identities and relationships; whereas in other phases they become more generally exchangeable, like emblematic types. The generic and the specific were also explored by Daniel Miller's Material Culture and Mass Consumption (1987) which, following Georg Simmel, characterised culture as a process of objectification, between the problematic, overwhelming mass of infinite things and the personal intimacy of possessions.

These works opened up new methodological possibilities for the study of culture. Anthropologists study culture, but if culture does not reside only in humans there are ever more ways to investigate it, beyond sharing moments with people during ethnography. Nonetheless, there have been very few attempts to study the social lives of specific objects, and few have considered what this can and cannot achieve. Most follow-the-things approaches have looked at general classes of thing or things as they are experienced by people, not as individual objects. Perhaps anthropologists feel more comfortable when things are generic and fall into fairly clear categories. This means we 
can avoid challenging certain conceptions about culture as a patterning of meaning, and the capacity of persons to be unique and specific against the background of a typical world. The exciting prospect of examining the lives of particular objects was also to some extent stopped prematurely when Appadurai (1990) published his analysis of modernity, emphasising the idea of global 'scapes,' or flows, and the disjunctures between them. During the ensuing debates, Marcus (1995) set out several kinds of follow-the-thing approach: the commodity chain (Wallerstein 1991), the political economy of a commodity (Mintz 1985), studies of globalised taste or style (Feld 1994), and Latour's actor-network mode of critical inquiry. None of these focus on individual objects' lives as a priority.

The methodological opportunities of following things was thus co-opted into grander projects aiming to theorise culture. Writing object biographies does not necessarily advance a particular theoretical agenda in the way that Marxist or Structuralist methods support a particular theory. Rather, like Abu-Lughod's 'ethnography of the particular' (1991), it presents a critique of culture as systemic. Although object biographies focus on material objects, they demonstrate the insignificance of things as much as their significance and can lead to a range of ways of framing the culture concept, as this chapter will later discuss.

We have many ways of following things, but very few published studies of specific, ordinary objects' biographies in anthropology, unlike in disciplines such as archaeology and museum studies. One exception to this is Stallybrass's (1998) extraordinary commentary on Karl Marx's ideas of commoditisation and alienation, through tracking the social life of his overcoat. Karl Marx pawned his coat when he needed cash and then recovered it from the pawn shop when he had money again and felt the need of the thing. A smart coat was necessary to enter the library where he wrote his most famous works. Yet, ironically, in those same works, Marx painted capitalism as a world of anonymous commodities and one-way commoditisation, not a world where objects are commoditised and re-personalised over and over again. Other exceptions worth mentioning are the anthropology of art, of craft, and of heritage, each of which often examine individual objects, as does European ethnology, which commonly explores folkloric heritage artefacts. Yet these fields tend to examine things of communal or transcendent value, and handmade things, rarely the banal mass-produced objects that typify commoditisation and the intimate quotidian lives of most people. Fragmentary object biographies also feature anecdotally in many ethnographic works, but such partial biographies are asides, rarely recognised as a deliberate method.

This chapter discusses the Object Biography, an intellectual exercise examining and describing the social life of one particular object. To write an object's biography is a critical methodology, a deliberate tool more than a paradigm. It is a method in that it is an action, something for a researcher to do intentionally to build research information. When I assert it is critical, this contradicts the commonly held presumption that critique must be an act of 
theorising. Methodologies can be critical as well. Object biographies do not simply lay out chains of facts for people to think with. They deal with truths more than facts, like human biographies, histories, or the clandestine genre entitled 'true crime.' An object biography is a deliberate methodological undertaking aimed to raise the critical perspective and alternative frameworks for understanding culture.

Each year anthropology students at UCL write object biographies as a part of a course on mass consumption, and I draw upon these here. I describe one particular example, a biography of a toothbrush. This example allows us to examine what kinds of issues an object biography is good for thinking about.

\section{What is this method?}

Writing an object biography involves choosing a specific thing and describing a range of different moments or periods in its life. One quickly realises that every object is very different, and the ways the stories emerge and are written are different. Fifty cans of Coca Cola provide at least fifty separate biographies, so one must be selected. The story before arriving in a shop may be similar, but one can becomes part of a packed lunch, another a party, another is thrown away, another gifted, another damaged. It is impossible to know about every period in an object's life - you were not there - and so these are life 'stories.' This is part of the exercise, since moments and phases in a thing's life are witnessed and experienced by different people. These communities, people, places, and purposes comprise separate social environments, each of which makes sense in its own terms. When an object's biography narrates life phases, such as when it is made, when it is in a shop, or when it is in a home, that journey cross-cuts separate human worlds, and so some periods are often imagined, assumed or suggested. It is always preferable to write based on observation but, at any point, other past and future moments and social domains may appear as inferences, such that the imagination of a social pluriverse across the many moments in the life of a thing features large in any narration.

As the chapter by Jeevendrampilai, Burton and Sanglante (Chapter 7) makes very clear, the lives of objects necessarily happen in parallel with the lives of humans (Tilley 2007). A biography describes uses, identities, experiences, and relationships that different phases of its life enable. The thing might be at times a tool, a gift, a product, a good: such words describe its social state in relation to the conceptions of people. Often there are phases and states that are unique. The biography considers what aspects seem important at these different times, and how it represents something that seems like a general type or specific thing. The term 'biography' then is important because we are not only interested in setting out a sequence of events, or how objects age and develop over time, but in the succession of their social states. This is similar to the way that the biography of a person will not place equal emphasis on every year of their life, but consider momentous events and key achievements 
or difficulties in life that are particularly significant. A consideration of value(s) is especially important, because of the importance of moments when a thing moves between being unique and being a representative type. At such moments, we witness the interchangeability of things, as carriages of meaning and as mutually exchangeable.

Being intrinsically temporal constructions, objects' lives also feature futures. We do not know exactly what lies in the future, but because objects have effects (agency, we might say, although agency is temporally uneven), they seem to obligate certain futures. In the current environmentally conscious era, for example, many objects oblige people to dispose of them in certain ways, shaping peoples' actions. The futures of possible pollutants lend them a palpable sense of danger. Similarly, many objects have the sense of only being exchangeable under certain circumstances. The future of an object in a shop is to be bought or otherwise stolen, constructing ideas of theft. The futures implied at different moments in an object's life are suggestive of value, of morality, and proper actions, and how people ascribe these to the object. These as-yet-unknown futures form a legitimate part of biographies and illustrate the force of their lives, based not upon facts but on apparent temporal truths.

An object biography is mostly descriptive. Description is not intellectually neutral; it is a purposeful act. In MCS, objects, things, and materials are understood as active in human knowledge processes and essential to culture. There are multiple paradigms for this: culture as objectification (Miller 1987); Simmel's (1971[1903]) notion of objective culture; Gell's (1998) and Küchler's (2013) conceptions of the distributed mind or, alternatively, Malafouris' (2013); Knappett's (2005) locating of meaning in the affordances provided by networks; material culture as text-like (Hodder 1989); or Henare et al.'s (2006) arguments about things as thoughts in themselves. Bourdieu (1977, 1984a) should take most credit for making the point that material objects are intellectually active. Following these authors, to describe material culture is also to model, offering possibilities to test ideas and interpretations. Every anthropologist should be a competent observer of minutiae, but we are trained to value the grand interpretive statement above the more challenging and potentially more critical descriptive mode.

In spite of the range of work mentioned above, cultural theories of commoditisation and its diversity remain inexplicably neglected (excepting Miller and Bourdieu; and see also Hart 1982). Ethnographic methodologies often maintain an implicit fiction that material objects have arrived in a place in order for people to build cultural ideas around them, and the idea of the commodity remains culturally passive.

An object biography is therefore very different from other methodologies but can overlap with other methods. It is not a design history, commodity chain, or a structural analysis, each of which discusses generic classes of things. It is not a straightforward ethnography, which emphasises contextual and contemporaneous understandings. So too do phenomenological approaches 
that examine the 'emergence' of separate things into human awareness. It is not a chaine opératoire, which scrutinises how things come to be as they are. Nor is it an actor-network approach, which incorporates many different agents, actants and objects into its scope. An object biography, by contrast, is focussed on an object, rather than persons, examining a specific life of a specific object over time, and is more about exchange and transmission than it is about productive work.

To illustrate, let me share with you the story of Anna's toothbrush ${ }^{1}$. It is retold here in my own words and, as will be clear, it became the story of several brushes' lives. Anna did not discuss the making of the object, but began with her own first encounter with it; and she only implied its potential future life. She focussed in on the brief period when a toothbrush encounters its 'significant other,' a particular person. Toothbrushes are very culturally active and visible for a brief time, generally only months. They can exist for many decades afterwards, and travel extensively, but their time 'in the light' of human life is all too brief.

\section{The life of a toothbrush}

The toothbrush was bought cheaply in a discount supermarket in London, one of two in a packet. The supermarket was selling 'two-for-a-pound' toothbrushes, one coloured pink and one blue, in each packet. Buying two was actually cheaper than going to a chemist and buying one good quality brush, but Anna was just thinking she needed a toothbrush for a short time, because she herself felt transient while studying in London. She was not concerned about quality, or the branding, and gave no consideration at all to the fact that perhaps cheaper goods might imply worse labour conditions or other ethical issues. It was 'just a brush.'

At home, she chose the pink toothbrush. This was in spite of the implicit gendering of the toothbrushes, which would suggest that, like the toothbrushes, people live in pairs, similar in substance but appearing different. Usually Anna buys blue toothbrushes. That has been her general habit, rejecting the 'pinkfor-a-girl' notion but, in this instance, she felt the pink one was 'more her.' Hence the pink one was installed in a mug beside the bathroom mirror. She lived in a rented student accommodation in which the toothbrush was one of the few objects that was 'hers.' Like in a hotel, she reflected, where the toothbrush is one of the things you bring with you; toothbrushes are an indication of 'where you are staying,' carrying with them the intimacy of 'home,' while not constituting home as such. The toothbrush indicates a certain kind of dwelling and inhabitation, and the presence of a toothbrush changes a place.

The new pink brush displaced her previous (purple) brush. In London, one person uses one brush. This unexpressed one-to-one principle only becomes manifest in the comparisons made between brushes. The purple brush, yesterday seeming very clean and functional, suddenly looked old, worn, and useless by contrast with the pink. Nonetheless, she did not throw it away, 
haunted by a notion that plastic toothbrushes should be disposed of responsibly, as if every toothbrush has a turtle's name stamped on it. She also had a sense that the purple brush was still 'hers,' intimate to her, and that perhaps it still might have a use, perhaps for household cleaning. Even when demoted to pseudo-rubbish, the purple brush still exercised a feeling of possibility and obligation over her actions. The difficulty of throwing it away is a sign of the times, and the public consciousness about plastics as 'polluting,' but there was as yet no clear knowledge of how to properly dispose of an object like this, made from several compounded plastics. In the 1990s, it would have been easy to simply put it in the bin. By the 2020s, it is possible that it will, again, be unproblematic, if systems for proper plastic disposal exist. Yet in 2017, this purple toothbrush resisted disposal, and became mere context for the pink brush.

The pink toothbrush travelled with Anna. It went to France, mediating the relationship between Anna and different places, producing flexible and shortterm moments of dwelling. The presence of the brush in friends' bathrooms and hotel rooms established a temporary anchor as she visited, and it was one of the things that enabled her to make those spaces, for a short time, her own.

The blue toothbrush, the twin to her pink one, Anna gave to her boyfriend to use. While he had stayed over before, the presentation of his own toothbrush to keep in her apartment felt like a significant moment, a small step from mere intimacy towards a slightly longer-lasting kind of relationship. It is difficult to see what other kind of object might perform the kind of relationship achieved in this action. It is also difficult to specify in words exactly what kind of relationship this act of giving achieved. It is a relationship between people who give one another toothbrushes to keep in one another's homes. Sometimes objects, and their lives in exchange, can be much more subtle and specific than language, and communicate for themselves.

At a later date, a different friend of Anna's stayed over after a night out, a girlfriend. Faced with a choice of toothbrushes to offer her, Anna decided the best one was the pink one (Anna's own), rather than the blue one (her boyfriend's), or the unfortunate purple one. Her girlfriend was unaware of the history of these toothbrushes. It made no difference to her, but for Anna there was a lingering sense of intimacy in the rinsed and washed plastic bristles. Anna preferred that she herself use her boyfriend's brush, which had been at times infused with his saliva, and that her girlfriend used the brush which had been infused with Anna's. This also seemed like the appropriate or polite way to use the brushes, an arrangement that would suit everybody, and nobody would mind.

\section{Reflections on the life of a toothbrush}

This narrative illustrates some of the ways an object biography can be used effectively. Although it does not depict the entire life, it takes account of the long-term through implication, of manufacture and of its life as rubbish 
(beyond 'disposal'). Importantly, even in a short space of time, the narrative considers several moments of exchange or exchange-like actions. These are not all moments that correspond necessarily to grand structures of value (spheres, following Appadurai), such as the transition from shop to home. There are also moments of exchange that are particular and intimate, and some of which seem transient, while others could be permanent. Other moments involve value transformations and are suggestive of exchange-like actions, but are not actually exchanges between persons, such as the displacement of one toothbrush by another. In such instances, culture is emergent and unpredictable, and yet still apparently patterned with meaning.

The narrative focuses on the object, but it never falls into the trap of thinking that objects live their own lives independently of people, nor that people are fully in control of them. The toothbrush achieves social and cultural effects, states, relationships, and identities that other objects might not, and it acts 'back' upon people, so to speak. There is serious anthropological content here: at the heart of anthropology are human relationships, but it is mysterious how one can actually build a relationship with another person. Equally mysterious is how relationships produce certain kinds of persons. In this instance, one way in which human relationships are built becomes evident. After Anna gives the blue brush to her boyfriend, their relationship is different from before. It is a small but significant reflection upon the 'substance' of enduring social connection. I would contend that in this instance describing the life of the toothbrush is more effective than using words to describe the relationship directly, as if the relationship were a thing in itself rather than a compounded cultural phenomenon built from experiences and things in motion as well as words. As anthropologists, when we model culture and society it should preferably be done on purpose, rather than an unconscious by-product of our word-based ways of working. Consequently, the way in which one privileges the word 'boyfriend' or the description of the giving of a brush - these matter. An anthropological description can claim to be either an observation or an analysis; to make the same point, but to specify the story of the brush is to make a claim for understanding that simultaneously situates the social scientist as observer, aware of their own viewpoint, while to emphasise 'boyfriend' as a term makes a claim to transcend the immediacy of context.

Importantly, in these engagements with people it is clear through the narrative that the toothbrush itself can move on. While it sometimes has a tremendous sense of human importance, because every toothbrush does have one significant other, the constructed quality of this cultural edifice is also clear. The brush's owner for this brief period, Anna, certainly considers it important, but for many phases of its life she does not feature at all. It may have existed for months or years previously, perhaps in many countries, and it can exist for a century afterwards. While Anna's memories may endure, and the changes in her relationships and experience may be permanent, the brush itself can move on quite easily, unencumbered by memory, regret or 
attachment. The narrative approach then manages to conjure an 'object perspective' through which it achieves the effect of decentring its cultural perspective away from the subjective point of view of one person who owns it. This viewpoint advances the critical approaches to personhood and self, as the editors of this volume discuss in the Introduction.

This 'object view' is also the anthropologist's view, a narrative device premised on the bizarrely common anthropomorphic idea of objects having 'social lives.' A toothbrush is not alive, but it does have existence and is involved in events. This device enables a positional shift of the anthropologist, situating themselves in articulation with, but separate from, informants. Hence, the object view can be an effective device for some purposes. This 'object view' is often created before the author knows what their analytical or interpretive argument may be, but it opens up a space. Rather than the relating of a single sequence of material facts, or the dual accounts of informant and anthropologist, divided by human difference, the object biography seems to produce mutual truths within a fictional framework - persons' and object's.

The fiction of anthropomorphism, whereby author identifies more closely with object, is often comedic. Much of the story of this toothbrush's life seems ironic or whimsical, even at times when very serious issues are addressed. Within one object, we allude to the destruction of the global environment by plastic, and of enduring human partnership, but these are microcosmic and underwhelming. Object biographies may seem serendipitous, risky, non-normative, even ludicrous, as they conjure their unusual object-centred lifeworlds, and this enables us to question cultural understandings that we otherwise take for granted. As descriptions, object biographies often appear as a mixture of moments and, like all biographies, they may end in pointless death, rather than at the moment of greatest success. As stories, object biographies may have a critical purpose, but it should be fairly clear that this purpose is primarily that of the storyteller.

Importantly, a good object biography does not make solid claims beyond the scope of its observations. It comprises a sample of one. Yet because typicality and specificity are social states, most objects evoke, or are in dialogue with, cultural typicality at moments in their lives. Any interpretation is limited in its scope. This is a method for challenging or testing typicality more than asserting it. And knowing the basis for one's knowledge and its limitations is just as important an anthropological skill as a talent for grand interpretations.

There are many different approaches to the study of material culture. Object biographies offer a distinct method, notable for five characteristics.

\section{(1) An exoteric method}

Most MCS use what I characterise as 'esoteric' methodologies. That is to say that interpretation usually involves reading 'beyond' or 'into' material things. There are different ways of doing this: some theorists consider (and critique) a tendency to separate out systems of signification into material 'signifiers' and immaterial 'signified's (Keane 1995, 2006). 
The ontological turn (Holbraad and Pedersen 2017) works to collapse such distances. Other approaches consider the indexicality of things for human actions, intentions, purposes, or uses, as well as representation and semiotics (see Carroll, Walford, and Walton, Chapter 1). What many methods do therefore is hinge upon the idea that the interpretation of things means accounting for them in terms of persons, human bodies and minds, which may or may not be present. These kinds of approaches are 'esoteric' in the sense that they treat material culture as a mysterious object that needs to be accounted for in other terms, and therefore strive to create a sense of depth.

Although object biographies can suggest depth, they really come into their own as a methodology capable of collapsing depth into a more straightforward sense of being 'just things.' This is because most objects' lives involve sequences of different social spheres and states. While at any particular moment, for certain people, there is often a sense of deepening profundity and significance, nonetheless equally often the object progresses to a new domain, leaving behind the previous values and meanings.

An object can become very personal, intimate, and special. In many object biographies, people talk of love, of memories of special events that attach to souvenirs, of the inalienability of objects and the unthinkability that the connection of a person to a thing will ever be broken. But the unthinkable happens routinely as objects move to new people, and their past lives are forgotten. This kind of moment is one where the profundity of culture is rendered from deep to shallow. At one moment the thing can be explained culturally or accounted for through its relation to people and, at the next, it may be simply another thing, ready to be reappropriated. Some things retain human connections, many do not. Context evaporates. Such moments are exoteric in the sense of not being mysterious and deep, but self-evident and shallow, but nonetheless just as culturally operative and worthy of anthropological investigation and understanding.

The exoteric effect of biographies may be most evident around personal possessions, but similar processes happen around brands and objects in shops. To take just one brief example, one UCL student related how a pair of special branded Japanese socks, whose manufacture was inspired by the traditional techniques and knowledge of Czech grandmothers, and which evoked a sense of home, came to be used as cleaning cloths.

What this amounts to is that if you want depth, you may not need object biographies, but if you want to challenge depth, consider their merits as a critical method.

\section{(2) A method that challenges norms}

A second, and related, use of the object biography is to question the sorts of categorical norms that interpretation often evokes. In our toothbrush 
biography, there are several recurrent ways in which a toothbrush's life evokes gender norms but need not correspond to those norms because what happens is not predestined. Queer theory (Graham 2014; Boellstorf 2007) and feminist thinking (Davis and Craven 2016; Strathern 1987b) have worked to undermine and challenge normative presumptions about culture and revealed its creative potential. The many-headed Foucauldian currents in cultural theory have been especially important in this. Object biographies often scrutinise and challenge such norms 'from the inside.' A study of a single toothbrush cannot hope to justify any claims about grand categories like heterosexuality, coupledom, or other identities. But what is described is the constitution of a particular relationship and its unfolding, its expectations and understandings, and the particular way its course is developed and explored. We witness here a constitution of a heterosexual femininity which, in other methods, would appear as a grand cultural category, but here is a single instance of an emergent identity in the micropolitics around the thing. The biography casts a relationship, usually described as normative, in a decidedly odd (but not queer) perspective. Presented with a world of objects that constitute cultural resources people in a sense 'grow into,' but also are involved in creating, roles, identities, and relationships.

An object biography at its weakest describes the social life and then accounts for it using conceptual categories such as 'gendering,' 'masculinity,' 'femininity,' or a host of other grand ideas. A better biography asks how these grand ideas are constructed at a certain moment, and hence questions how they are valid. In a life that moves between generality and specificity, it is often the stereotypical potency of such objects that itself comes to be the resource for new meanings.

\section{(3) A method that crosses human-constituted boundaries}

It can be exceptionally difficult for us to clearly perceive the particular cosmologies and cultural worlds that surround us, but establishing some kind of objective perspective on domains of cultural existence is one of the prime exercises of anthropology. Breaking open such worlds is especially difficult around banal, everyday objects. In the study of consumption, there is also a prevailing and dominant 'consumer' narrative. The destiny of things in this narrative is to be chosen, possessed, and consumed by people, and to form building blocks in the domestic shells that constitute their social existence.

Many material-culture methodologies serve essentially to support the idea that objects' most significant role amounts to participation in singular arrays and contexts that have persons at their centre. Object biographies, by contrast, very deliberately construct a framework in which these boundaries and contexts are pierced, rendered permeable and flexible. Hence, it becomes possible for the analyst to be able to gain some traction in stripping away and dissecting these webs of significance, 
to paraphrase Geertz and Weber. As Jeevendrampilai, Burton, and Sanglante (Chapter 7) make clear, in moments of exchange objects can evoke networks of relationships and problematically cross the boundaries of human worlds and, by doing so, play with preconceived notions of commoditised and non-commoditised relationships.

The clearest example of crossing boundaries for most objects is when they transition from making shops to making homes, from institutional property to personal possessions. Yet this is only one phase in an object's life. A biography that tells us about how something is bought, consumed, and ultimately becomes a part of one's identity, and then ends at that moment, has probably only told us what we might already have guessed. The narrative becomes more about an individual's psychology, and at the expense of social understandings. Alternatively, we can frame that consumption story by examining the institutional worlds of factories, of shops, and of waste processing. In many shop cultures, people present themselves as 'staff,' wearing uniforms, and spend their time arranging and replenishing goods in displays that make the objects look similar and anonymous. These finely tuned cultural environments prepare goods for the possibility of personalisation and maximise their capacity to move between contexts. Most objects pass through many hands in their lives, moving between commerce and homes, between homes, between generations, in and out of heritage centres, exhibitions, and performances, between countries and across landscapes. National borders move around them, and geography changes.

Travelling through social worlds, a sock becomes a cleaning cloth, a rose becomes a perfume gift, a cardboard electronics box becomes a bed for someone who is homeless, a tacky holiday souvenir becomes your grandchildren's family heirloom (see Frow 2001). In examining the transcendence of boundaries, the parallel social pluriverses are counterpoised and exposed. Some cultural models conceive of a world connected by cultural flows, networks, or relationships. A biographical approach, however, comes into its own in a world constituted by partitioned bubbles (Sloterdijk 2016) or microcosmologies.

\section{(4) An intimate methodology}

When it is a commodity, an object represents a generic type of object, and it also reflects persons as types, such as when a person is a 'consumer,' a 'middle-aged male householder,' or a 'driver.' When the same object is a personal possession, it becomes irreplaceable, something no other object really can duplicate, and which fits into a particular world of objects. Specificity is a dimension some methodologies explore well, including ethnography, but not others, such as semiotics.

In examining the specificity of material things, object biographies cast things in a very intimate light. They are often close to home, capturing moments when the treatment of material things is (often unexpectedly) 
charged with the force of obligation, the requirement to do the right thing. In the toothbrush biography, we saw that all three of the brushes, the pink, blue, and purple, each oblige certain behaviours. Using the wrong toothbrush or allowing others to use the wrong brush feels forbidden; taboo. This quality of encountering an unexpected sense of taboo is not uncommon in object biographies. One way of thinking about this is to consider it in the light of Mary Douglas's (2002[1966]) famous analysis of dirt, as 'matter out of place.' Almost by definition, an object biography appreciates the movement of objects through space and how, at different moments, the social boundaries and rules change around them. There are moments when an object has to find a new normative position within a new social order, and the interesting thing is that the rules and social orders seem to change periodically and of necessity. The potential closeness of matter in an object biography can give an intimate sensation of potentially unpleasant self-awareness.

Appadurai (1986a) reminds us of Simmel's observation that the desire for objects sometimes lies in the degree that they seem to resist our possession. This observation does not only apply to single subjectobject relationships, but characterises the world of the metropolis (Simmel 1950). As people pass through intensely occupied urban environments, the object world is pervaded by senses of possession and resistance. A complicated ballet governs as people pass, touching walls, not touching cars, selecting objects in shops, gazing at displays from a distance, brushing against other pedestrians, talking, not talking. Through this humanly constituted world of sensation, material obligation, and resistance, objects traverse and violate in ways utterly unlike humans would. Many objects are intimate, coy, and resistant one moment, and unexpectedly close and personal the next, testing social taboos.

\section{(5) A methodology for the politics of the Anthropocene}

If there are reasons why object biographies are good for examination of the intimate, private, specific, everyday life, what Miller (1987) calls the 'humility' of objects, they are also a methodology to examine contemporary public politics (see Carroll, Walford and Walton, Chapter 1, discussing participatory politics and temporality). The Anthropocene, of course, refers to a period of global history in which the nature of the globe is constituted and defined by human action. As a scientific phenomenon, the Anthropocene describes how measurable changes in the world can be explained as being caused by human activity. As a cultural phenomenon, the Anthropocene describes the global recognition of this fact and, consequently, a re-orientation across human cultures of what is 'natural' and how to relate to it.

The object world in this framework comes to appear as a set of manifest resources and materials (Drazin 2015). The plastic of toothbrushes thrusts itself into peoples' attention, for example, recognisable and 
meaningful alongside the object's role as a useful tool for certain shortterm purposes. At the same time, objects are subject to evaluation in panhuman terms, according to parts they all play, however small, in the history of the globe. Like biographical approaches, the cultural Anthropocene always presumes that there is a moment 'before' the current one, and that there have almost always been human hands working in the world before our own. More importantly, however, we need to have methodologies that ask about what happens to things 'afterwards'? After their explicit and conscious role in human lives, what happens culturally to objects?

The object biography framework makes conceptions of waste, disuse, obsolescence, repair, and renovation more accessible to anthropological inquiry. Evidently, often it is speculative or fictional, as we have discussed, but it is nonetheless an important methodology to consider.

\section{Conclusion: Why not object biographies?}

Every object has a story, and there are many I wished to share in this chapter but have not been able to. The paper clip, the hair band, the seemingly immortal cardboard box, the inconceivably kitsch resin dog, the unsellable handmade shawl, the printer paper, the disposable razor, which is not. None of these biographies remotely resemble that of Anna's toothbrush. Biographies are written in the first-person voice (without being autobiographies), and in the second and the third. They are poetic, dry, witty, tragic, flat, ordinary, and frequently overblown. Every object's story seems to compel, and deserve, attention, because the richness of human experience only really emerges through looking at the material world in its detail. According to whichever object is selected, it offers the means to explore and question personhood, the body, identity, charity, architecture, property, suffering, memory, or a hundred other things. One of the methodological contentions of the renaissance of material culture writing in the 1980s and 1990s was that the project of building broader, culturally comparative interpretations, and the project of observing with clarity the minutiae of everyday life, should be mutual. The big picture and the miniature, the novel and the vignette, are different exercises in scale but not in critical essence.

At times, grander theorisations can obscure as much as they reveal. This has been the case with studies of exchange. A potentially infinite range of social and cultural events, relationships, modes of building identity, experience, memory and purpose, have tended to be condensed into ideas of commodities, gifts, and discourses of the consumer, the market, and the state. The language of values is much richer and more flexible than that of exchange.

Object biographies are not a catch-all methodology. They will not produce a major theory. They are a unique methodological tool, with a specific critical edge, to be used with some awareness alongside other approaches. They challenge thinkers to observe, and to acknowledge the extent and basis of their own knowledge. While in theory it is possible to write parallel comparative 


\section{Adam Drazin}

biographies, in practice one finds that mutual touchstones between two narratives seem rare and serendipitous. I have yet to read a single object biography in which the life of a thing unfolds in a predictable fashion, and I am tempted to suggest that stereotypical objects or categories of objects simply do not exist for the purposes of studying culture. If nothing else, writing an object biography or two will help shake up your thinking and compel the realisation that 'things' are not as you thought they were.

\section{Acknowledgements}

I would like to thank my many students - including Anna - for their creativity and ingenuity in exploring the possibilities of object biographies as a methodology, and some of whose work is mentioned in passing.

\section{Note}

1 I am deeply appreciative of Anna's willingness for me to draw upon and elaborate her original object biography. Anna is a pseudonym. 